\title{
Port specialization and connectivity in the global maritime network
}

\author{
César DUCRUET \\ French National Centre for Scientific Research (CNRS)
}

Pre-final version of the article published in Maritime Policy and Management (2020)

https://doi.org/10.1080/03088839.2020.1840640

\begin{abstract}
While ports of the world are more or less diversified, the influence of traffic diversity on the global port hierarchy and maritime network is not yet well understood. This research uses a complex network approach to analyze the interplay between no less than 20 shipping traffic types connecting more than 1,600 ports. A database covering about 155000 daily movements of 24321 vessels in 2008 is used to construct a global matrix of inter-port shipping flows. Main results show that the global network is highly dependent on more diversified nodes, which in turn catch the most traffic and exhibit higher connectivity. It also underlines the role and nature of specific shipping segments as layers of an allencompassing maritime system.
\end{abstract}

Keywords: complex networks; connectivity; maritime transport; port hierarchy

\section{Acknowledgements}

The research leading to these results has received funding from the European Research Council under the European Union's Seventh Framework Programme (FP/2007-2013) / ERC Grant Agreement n. [313847] "World Seastems".

\section{Introduction}

Ports of the world have in common to serve as crucial transfer nodes handling most of international trade volumes. As the quantity and nature of handled flows greatly varies among them, understanding the relationship between traffic size and traffic diversity is of paramount importance. Total throughput is the most common port performance indicator, and is relatively well accessible to researchers willing to run international comparisons (Tongzon, 1995). In contrast, the breakdown per commodity types is only available for certain ports, countries and regions, and the harmonization of such localized databases, to overcome differences in units and items, forces scholars to work with broad traffic categories such as liquid bulks, solid bulks, and other (Ducruet and Itoh, 2016). Another important facet of port performance is connectivity, which is widely advertised by port authorities, but has long remained poorly researched by the academic community (de Langen et al., 2007).

This article thus wishes to further understand the mutual relationships between traffic size, traffic specialization, and traffic connectivity. In terms of size, ports may be favored by endogenous factors, such as the proximity to natural resources for export and the facilitation of transport accessibility 
through multiple modes (e.g. river, rail). The size of the market area or hinterland also plays a role, should it be concentrated around the port itself (e.g. large city) or spread further inland. Exogenous factors relate to the capacity of ports to be embedded in the networks of transport actors or "intermediacy", as a complement to the aforementioned self-generation power of traffic or "centrality" (Fleming and Hayuth, 1994). Intermediacy and centrality are likely to combine with each other in the case of large ports, while the stronger emphasis on intermediate functions better relates with the transshipment function, less in line with the local economy but dependent on the port infrastructure itself to concentrate flows for intra- and interregional traffic redistribution (Rodrigue and Notteboom, 2010; Slack and Gouvernal, 2015). Traffic inequality among ports is a recurrent subject of research in transport studies, notwithstanding the difficulty to measure the difference between transshipment flows and trade flows (Notteboom, 2006).

Port specialization studies are numerous in geography (see a review by Ng and Ducruet, 2014), mainly in the form of monographs that documented, back in the 1950s, the different functions of ports associated with their hinterlands and forelands. Ports were coined by their dominant traffic or economic base, such as industrial ports, passenger ports, coal ports, and even coffee ports. However, "geographers interested in the relative stature of ports have speculated for years about the best measurement for comparing and classifying ports" (Rimmer, 1966). Based on the assumption that "port commodity specialization is primarily influenced by economic functions, but also by unique geographic considerations" (Marti, 1985), geographers proposed to categorize ports using specialization indices to investigate their potential for adopting containerization. Other scholars, in geography and economics, applied various "weighting rules" to the tonnage of selected ports, to improve their comparability in terms of potential economic impact and value creation (Charlier, 1994; Haezendonck et al., 1999). Such studies were mainly based on small samples of ports for which a sufficient level of detail was available. At the European level, Ducruet et al. (2010) found a significant correlation between commodity diversity and traffic size, albeit many exceptions. Numerous small and medium-sized ports situated at the periphery and/or on islands could reach a comparable traffic diversity than Rotterdam and other large mainland gateways, thanks to their captive hinterland, protected from competition (see also Ducruet, 2020 for a global perspective).

Relationships between port connectivity and specialization were more recently explored through analyzing the situation of ports within maritime networks composed of different layers. A majority of studies concentrated on one segment only of maritime transport, mainly container shipping, while others analyzed different segments taken separately. Kaluza et al. (2010) for instance compared the global network structure and community distribution of oil tanker, container, and dry bulk global networks, while Pais Montes et al. (2012) compared general cargo and container networks. Other studies looked at, for instance, cruise networks (Rodrigue and Notteboom, 2013), liquefied gas networks (Peng et al., 2020) and oil networks (Peng et al., 2019). However, such works did not investigate how the different layers of maritime circulation are interconnected nor did they look at how the centrality of ports varies across layers. The multilayered perspective was first proposed by Ducruet (2013) using five different layers (containers, general cargo, solid bulks, liquid bulks, and passengers/vehicles). Among the findings, it was showed that ports handling more vessel types concentrate more traffic, are more central, have longer interaction range, and are more densely connected with each other than the rest of the network. In turn, more diversified inter-port links are much shorter, more voluminous in terms of traffic, and are more crucial (bridge role). In particular, container shipping has the highest number of shared links with other types and connects more diversified ports on average, contrary to other layers that each follow a specific configuration. A more dynamic approach was proposed some years later based on six layers (Ducruet, 2017) demonstrating 
the stability of the previous findings over time, notwithstanding a slight decrease of the inter-similarity among layers from the 1970 s to the 2000s.

The aforementioned studies, still, focus on a simplified view of maritime transport made of much aggregated sectors. It is therefore the goal of this article to examine more in depth the diversity of flows and their interdependencies at the global level, and at the local level of individual nodes. We propose a novel analysis of no less than twenty different layers of maritime flows, using the Lloyd's List global database that tracked the daily vessel movements of 116248 vessels connecting 1666 ports in the year 2008. The main goal of the proposed research is thus to investigate the interdependencies among the different layers and their implications for port hierarchies. We also wish to test the vulnerability and robustness of the global maritime network - as an assemblage of all layers - with reference to the complex networks framework proposed by physicists (see Vespignani, 2010). This framework, derived from graph theory - a branch of mathematics - is useful to grasp the essential features of networks' topological structure in general, although multilayered networks (also coined multiplex or coupled networks) do not have a proper mathematical definition. Simple statistical measures and algorithms shall suffice to highlight the "inter-similarity between coupled networks" (Parshani et al., 2010). Having a more precise view of port specialization and diversity is also useful to overcome the lack of a systematic view on the matter given the scarcity of data, and therefore to provide port communities with effective benchmarks on their activity, in a comparative perspective. Which ports are the most diversified and why? To what extent is this diversity a factor of competitiveness? Should specialized ports diversify their activity?

The remainder of this article is organized as follows. Section 2 introduces in more detail the data source and the methodology for multilayer network construction. Section 3 offers an analysis of the interdependencies among the different layers, defined by the circulation of twenty different vessel types. Section 4 analyzes the robustness and vulnerability of the global maritime network using a different definition of layers that is, subgraphs of ports handling the same number of traffic types regardless of their nature. Section 5 concludes about the lessons learned for both network studies and transport studies.

\section{Analytical framework}

2.1 The global maritime network: a single system?

Analyzing jointly all maritime flows within a single network could not ignore the drastic operational differences among the various shipping segments. The global maritime network is, in fact, an artefact for several reasons. First, assembling all vessel circulations into a single system assumes that those circulations are connected, although in reality, vessels and routes may be operated on different scales, from the local to the global, and shipping companies may serve distinct markets without any overlap. In the container business, it was shown that the port networks of major shipping lines have distinct geographic logics on the world scale (Frémont and Soppé, 2004) and along certain routes such as Europe-Asia (Rimmer and Comtois, 2005). Shipping alliances form specific networks compared with single companies, as seen in the Caribbean and Mediterranean basins (McCalla et al., 2004).

Another issue to overcome for the joint analysis of different market segments is the fact that each of them is governed by specific operational, market, and economic aspects. For instance, cruise shipping is organized in the form of itineraries within particular regions, marked by seasonality, and targeting specific customers (Rodrigue and Notteboom, 2013). This implies that the network formed by cruise shipping is made of a scheduled sequence of port calls or loop, often lasting a week, with a careful 
selection of three to five (hub) ports depending on their respective proximity. Roll-on / roll-off shipping, carrying both conducted vehicles (e.g. trucks) and passengers with or without automobiles, but also ferries, usually operating over short distances to cross closed seas or channels. Shortsea or domestic shipping by such means can be considered as an extension of the continental road network (Torbianelli, 2000; Baird, 2010). They can palliate the islandic character of certain countries as seen in the cases of Greece, Finland, and Indonesia, where peripherality can be an issue tackled by national authorities (Makkonen et al., 2013; Frazila and Zukhruf, 2015; Tsiotas and Polyzos, 2015).

Another main difference is between liner shipping and tramp shipping, or break-bulk cargo and bulk cargo (Rodrigue and Notteboom, 2020). Bulk shipping is characterized by single origin, destination, owner, and client with irregular except for energy trades due to its on-demand nature, resulting in port-to-port connections. Liner shipping is organized nearly as the opposite, through successive calls along a chain of ports, with many cargo owners, based on regular schedules. Another main difference is that bulk shipping is more likely to be seasonal, as in the case of grain for instance, but also more influenced by market and trade fluctuations according to the price of commodities, like coal. Liner shipping is better tied to manufacturing and consumption. It also adopted, especially following the growing size of its ships at a time of sector liberalization and horizontal integration, specific hub-andspokes as well as interlining configurations to save time and cost. This resulted in a growing concentration of shipping lines' services at fewer large transshipment ports, in the search for the least deviation distance from optimal trunk lines (Rodrigue and Notteboom, 2010).

Thus, merging the different operational logics into a single maritime system remains very challenging and subject to false interpretations. There are ways, however, to construct a matrix based on Lloyd's data respectful of such differences.

\subsection{Construction of the global network}

As most segments of maritime transport function through direct port-to-port shipments, as said above, the main issue for our present research is to make liner shipping compatible with the rest. Despite their use of schedule data, most of the existing studies of liner shipping networks analyzed a network made of direct port-to-port connections (see Bartholdi et al., 2016; Huang et al., 2016; Wang et al., 2016; Pan et al., 2019). One exception is the work of Hu and Zhu (2009) on the global liner shipping network, where each vessel creates a complete subgraph (i.e. all ports called by the same vessel are connected), so that ports situated at both ends of pendulum services are connected (space-P), which would not be the case when reducing the network to direct port-to-port connections (space-L) (see Figure 1). In the end, the total network corresponds to the combination of all subgraphs. Ducruet and Notteboom (2012) provided an analysis of the topological difference between (a) and (b) in Figure 1, based on container vessel movement data. They particularly underlined that the network of port-toport connections (a) was smaller, sparser, less efficient, more hierarchical than the network of including both direct and indirect connections (b). It was then decided, in the present study, to retain the (b) configuration, which makes it possible to analyze jointly liner and tramp shipping.

\section{[Insert Figure 1 about here]}

The construction of the network was made possible by extracting vessel movement data from the Lloyd's List, on the basis of four complete months of movements for the year 2008 (i.e. March, June, September, and December). Despite the relatively dated character of the data, its advantage is to be highly representative of global shipping, as Lloyd's insures more than $80 \%$ of the entire world fleet. This database provides information about the daily movements of the insured vessels (ports of 
departure and arrival) as well as technical characteristics such as vessel capacity in deadweight tons (DWT). One first step of network construction is the definition of the different layers to be taken into consideration for the analysis of specialization. The original 159 types of vessels were aggregated into 20 broader categories, each of them constituting a layer of the maritime network. The categorization of vessels needed careful attention, however. Efforts were made to keep a relatively balanced importance of each layer, although containers, general cargo, and solid bulk could not have been subdivided further, as the carried products and commodities are not specified in the database. It is assumed that containers mainly carry finished, consumer goods, although a growing share of general cargo, reefer, and bulks is put into containers, while the general cargo category principally goes to semi-finished goods. The same applies for dry bulks, which may be composed of very heterogeneous goods such as grain or coal. Vessel data is thus not the same as trade data as the unit of reference is the ship, not the commodity. But one enormous advantage of vessel-based data is to allow the combined analysis of cargo traffic and passenger traffic using the same measurement unit. Links and nodes are weighted by the product of call frequency and vessel capacity in deadweight tons. Although this method makes the analysis closer to actual port throughputs by taking into account vessel size, it has, in turn, the disadvantage of taking for granted that vessels travel fully loaded and charge / discharge their entire volume at each port of call, the occupancy rate (as well as the number of empty containers for instance) and the port handling volumes being unknown and impossible to verify on such a large scale. Indeed, no database provides the precise throughput of ports globally.

Based on this categorization, the global maritime network is thus composed of 20 layers of inter-port maritime flows. The second step is to assemble all the vessel movements into one single matrix. Taking the example of Figure 1, we consider ports as nodes and inter-port voyages as links. We assume that vessel 1 and vessel 2 belong to distinct layers, such as cruise (1) and containers (2), with one port being in common between the two layers, for instance Naples. We repeat the same process of layer combination by iteration until the 20 layers are assembled into one single global system, each port being more or less present in such a multidimensional network. Last but not least, we aggregated ports nodes at the level of metropolitan areas, in line with Tsiotas and Polyzos (2018) in their work on the Greek domestic shipping network. We used the method of Ducruet (2020) whereby ports situated within the same urbanized area can be considered as forming one single spatial-economic entity or gateway. The extent of urbanization is one factor, to be combined with land accessibility when ports stand at some (minor) distance from the urban core. In the absence of a host city, the nearest city or regional economic center was used as the referent place, sometimes having multiple maritime terminals, while isolated ports were kept apart. Such an aggregation was judged necessary to get closer to the reality of economic systems, as for large cities such as London, many port terminals are scattered along estuaries but serve the main core market. Another example is Tokyo, which includes all Tokyo Bay ports like Yokohama, Chiba, and Kawasaki.

\subsection{Statistical background}

One first measure proposed in this study is the number of layers in which ports are situated, from 1 to 20. Although this measure has the advantage of simplicity, we complemented it by its weighted version based on DWT. For each port, total DWT equals the product of ship frequency and ship capacity. Referring to the relative diversity index proposed by Duranton and Puga (2000) for cities, we calculated for each port node, the Cargo Diversity Index (CDI), which is the sum of the absolute differences between the share of traffic $j$ in port $i$ and the share of the corresponding traffic $j$ at world level. The CDI is calculated as follows: 


$$
\begin{aligned}
& C D I=\frac{1}{\sum_{j}\left|C_{i j}-C_{j}\right|} \\
& C=\text { commodity share } \\
& i=1,2, \ldots, n ; j=1,2, \ldots, m)
\end{aligned}
$$

In order to understand the relationships at stake among the different layers, a multivariate analysis (Principal Components Analysis and cluster analysis) is applied to the distribution of traffic per port and per layer. It is a second step into the understanding of port specialization which, to our knowledge, has never been tried on such a large scale. Each Principal Component is characterized by its eigenvalue and will be selected as revelatory of traffic size effects and traffic specialization effects across the global port system. Principal components are the basis of a cluster analysis to go deeper in the understanding of the mutual affinities among traffic layers.

Another way to analyze inter-layer affinities comes from the field of complex network research. We use the inter degree-degree correlation (IDDC) proposed by Parshani et al. (2010) in their study on the inter-similarity between airline networks and container shipping networks. Based on degree centrality, which is the number of connections a node has with other nodes, the IDDC is the linear correlation coefficient (Pearson) between the degree centrality of nodes in layer $A$ and the degree centrality of nodes in layer B. In their analysis, degree centrality is unweighted as it is a simple count of the number of links (or edges) of each node (or vertice). The availability of DWT made it possible to calculate, like in the case of ports, traffic weights on links as the product of trip frequency and vessel capacity.

The basic meaning of the IDDC, ranging between -1 and 1 , is that positive values of $r^{A B}$ show that "highdegree nodes from network A tend to couple with high-degree nodes from network B and vice versa", while negative values show the opposite and "randomly interdependent networks correspond to the case of $r^{A B}=0$ ". The IDDC is calculated as follows:

$$
r^{A B}=\frac{1}{\sigma_{q}^{2}} \sum_{j k} j k\left(e_{j k}-p_{j} p_{k}\right)
$$

In order to study the vulnerability of the maritime network, we propose a different definition of layers than the one based on the 20 vessel types. With reference to the topological decomposition method employed by Zaidi (2011), it is possible to define a layer as a subnetwork made of nodes handling the same number of layers, regardless of their nature, should it be bulks or containers. The twenty layers are constructed in an ascending order, with the first one containing ports handling only one vessel type, the second one containing ports handling 1 and 2 vessel types, etc. until all ports are included (full network) for the final layer. Such an approach is based on Figure 2, where ports are differentiated by the number of layers they belong to rather than their specific traffic or commodities/cargoes. The distribution of ports is highly unequal, as 499 ports out of 1666 perform only one layer, and only one port performs all the 20 layers.

[Insert Figure 2 about here] 
The two types of layers, the ones based on traffic types and the ones based on traffic type numbers, will be analyzed through applying commonly accepted measures of network structure, borrowed from complex network analysis. The selected measures are as follows, with an illustration in Appendix 2:

- average shortest path length (ASPL), a measure of network efficiency corresponding to the average number of links needed to travel the whole network using all possible shortest paths among pairs of nodes;

- diameter, the number of links composing the longest shortest path;

- average clustering coefficient, the average probability for nodes' neighbors to connect one another, or, the proportion of observed triangles (or cliques) in the maximum possible number of triangles (or cliques);

- density, the proportion of observed links in the maximum possible number of links.

The average clustering coefficient and the density share a commonality; low values mean that the network is highly centralized and sparse. The same goes for diameter and average shortest path length, where low values suggest that the network is efficient, or easy to be navigated across.

\section{Inter-similarity in the global maritime network}

One first step is to check the effect of traffic diversity (number of traffic types handled from 1 to 20) on the connectivity of ports. This connectivity is measured in different ways: the number of multiedges, which counts how many links of different types connect the port to other ports (Newman, 2010), and strength, defined by the degree centrality of the port (number of adjacently connected neighbors) weighted by the product of call frequency and vessel size (see Barrat et al., 2004 for a discussion on the advantages of using weighted rather than simple networks). Based on a power-law fit, we calculated that the statistical relationship between the number of traffic types and total traffic (or strength) is significant $\left(R^{2}=0.634\right)$ as well as between the number of traffic types and the number of multi-edges $\left(R^{2}=0.775\right)$. The fact that larger and more connected ports are more diversified than smaller ports and less connected ports is confirmed by Figure 3 . Despite the relatively low correlation between cargo diversity index (CDI) and strength (0.265) and multi-edges (0.281), the percentile approach shows that as connectivity increases, the diversity of traffic also increases among percentiles, similarly to a Pareto distribution.

\section{[Insert Figure 3 about here]}

The number of multi-edges and layers can also be represented on a world map (Figure 4), showing that such variables are not randomly distributed. European and Asian ports in general stand out compared with other ports of the world by their superior connectivity and diversity, especially in the case of Rotterdam and Singapore hubs, but also London, Las Palmas, Busan, and main Japanese ports. In other regions, most diversified ports are often important cities (e.g. New York, Los Angeles) and/or the main port of the country (e.g. Jakarta, Rio de Janeiro, Mumbai, Dubai, Bangkok, Istanbul, Lisbon). Ports situated more inland, such as on rivers, estuaries, and lakes, are disadvantaged to receive large vessels and therefore remain highly specialized, as seen along the Amazon and the St. Lawrence Seaway.

[Insert Figure 4 about here]

Next, we run a Principal Components Analysis (PCA) on ports' strength (Figure 5) to unravel the affinities or oppositions among the different layers. The first principal component or loading factor (F1) 
exhibits a size effect with all traffics having positive signs, and containers being the best represented on the $\mathrm{x}$-axis. More interesting in terms of specialization effects is the $\mathrm{y}$-axis. Positive values on $\mathrm{F} 2 \mathrm{go}$ to bulks, especially crude oil, ores, other tanker, oil tanker, and gas, while negative values comprise passenger traffic (of which cruise), fish, vehicles, general cargo, and containers. The two principal components concentrate $37.98 \%$ of total variance and they express the overall logic of the global port hierarchy and specialization. Larger ports may exert all sorts of activities (F1) but some ports specialize in less valued, raw materials ( $F 2$, positive) while others handle lighter and more valued traffics (F2, negative). F3 and F4 give more importance to categories being poorly represented on F1 and F2, principally due to their smaller traffic size, such as wood, asphalt, service, reefer, and other. Ports handling such traffics are likely to be highly specialized in only a few categories. This is confirmed by the cluster analysis, which provides one cluster (1) made of multifunctional ports handling all possible traffic types, and eight other clusters with ports specialized in one dominant traffic category. Cluster (1) also contains the most voluminous traffic through handling the main markets (i.e. containers, dry bulk, general cargo), as other clusters specialize in niche markets (e.g. cement, livestock, fishing).

[Insert Figure 5 about here]

The next step is to apply the weighted inter degree-degree coefficient (IDDC) to our dataset. Given the size of the correlation matrix (20*19), we directly move to the results of a PCA applied on the network characteristics of each layer (Figure 6). We created two new variables for each layer, the average IDDC on nodes and on links. It corresponds to the average correlation between a layer's strength and all other layers, as a summary of its interdependency. Such variables are confronted to the aforementioned measures of network structure as seen in the figure. This time $91.71 \%$ of total variance is explained by the four main principal components or loading factors. Results are fruitful in many ways. We observe that larger networks by the size (nodes and links) also have the highest IDDC should it be on nodes or links, general cargo being by far the most representative layer. General cargo is not only specific by its larger size; it is also characterized by the fact that it is handled by most ports of the world. It means that sparser networks, topologically and probably geographically, form specialized circulation patterns not well overlapped with the core of the full network (i.e. cement, other, passenger, and fishing). Such smaller networks, in turn, are highly clustered (cf. average clustering coefficient) and therefore do not follow a hub structure. This is also the case of asphalt, livestock, cruise, and containers, with low IDDC and high density. While container shipping is the second largest layer by the number of links $(5,665)$, it contains a relatively small number of ports, reflecting upon its highly selective character, as not all ports are equipped with such dedicated facilities. Other layers having high IDDC on F1 are specific by their lower efficiency (high diameter and ASPL), such as oil tanker and other tanker. These layers are thus not well connected internally, as ships travel long distances to bridge origins and destinations, but also because the different parts or communities (or markets) within the layer are sparsely linked.

[Insert Figure 6 about here]

\section{Global maritime network vulnerability and robustness}

The main idea behind the analysis of vulnerability is to check how the global maritime network functions with or without nodes characterized by specialization or diversity. We calculated by successive iterations the network structure of each subgraph composed of nodes handling the same number of traffic types (layers). Figure 7 presents the results for the aforementioned measures as well as for the percentage of nodes and links contained in each layer. We see that the share of ports follows a logarithmic evolution while the one of links an exponential one. It means that links in general are 
more densely concentrated among diversified ports, so that the architecture of the network highly depend on such ports (which are also the largest). Ports are more evenly distributed across layers. While $50 \%$ of nodes are contained in the $5^{\text {th }}$ layer already, $50 \%$ of links are contained in the $12^{\text {th }}$ layer. This is in line with the findings of Ducruet (2013) showing that the most diversified ports concentrate world traffic and dominate the global network. In fact, only one single port handles all traffic types, Busan in South Korea, which is the principal gateway of the country and acts as a major regional transshipment hub in Northeast Asia (Frémont and Ducruet, 2005).

[Insert Figure 7 about here]

Density and clustering exhibit comparable behavior, with a continuous increase as more diversified nodes are added to the network. Without large and diversified ports, the global network remains sparsely connected and thus highly vulnerable. Short-range circuits are made of smaller ports connect each other by weak ties. Diameter and average shortest path length follow similar tendencies, starting with initially low values but rapidly becoming very high until the layer comprising 1 to 5 traffic types, followed by a continuous decline. Those measures of sparsity indicate that without diversified ports, the global network remains poorly connected and difficult to navigate.

A complementary view is proposed in Figure 8 , where the $1^{\text {st }}, 5^{\text {th }}, 10^{\text {th }}$, and $15^{\text {th }}$ layers are shown together with the world region to which ports belong. It confirms that the first layer, composed of the most specialized ports (handling only one layer), is poorly connected except for its main component. All subcomponents exist within one single region, also confirming that the most specialized ports have shorter interaction range than larger ports, and that it is impossible to speak of a global maritime network but of small, localized networks. Despite its bigger size, the $5^{\text {th }}$ layer shows a similar pattern, with Europe at the core of the network, but sparsely connected with rest of the world, except with Africa. Numerous tiny subcomponents still appear at the periphery. Large subcomponents comprising ports of the same region, such as East Asia, West Asia, North and Latin America remain poorly connected with each other. This explains to a large extent the peak values of diameter and ASPL as seen in Figure 5, as ports handling one to five layers are not sufficient to ensure global connectivity. The $10^{\text {th }}$ and $15^{\text {th }}$ layers show a comparable pattern, with a strong regional differentiation of ports and their linkages, but with an increasing topological proximity as the network grows and includes more diversified ports.

\section{[Insert Figure 8 about here]}

Next, network vulnerability may be envisaged though the analysis of the hierarchical structure of the network (Figure 9) in two different ways, the log-log plot of degree centrality in the single-edge network and of the number of layers versus the number (or frequency) of ports. The coefficient of the inserted power-law line shows that both statistical distributions are exemplary of a scale-free distribution, being negative and over 1 , although the scale-free dimension in highly hierarchical networks (i.e. containing many hubs) should range between -2 and -3 (Barabasi and Albert, 1999). The hierarchical dimension of the maritime network is attenuated by its spatial nature, as it is constrained by coastlines and distance, compared with other networks in other contexts. The distribution of ports by the number of layers reaches a high value (-1.758), as 499 ports out of 1,665 perform only one activity, and only one single port performs all 20 activities (Busan) as well as 19 activities (Tokyo), and five ports perform 18 activities (Singapore, Osaka, Dubai, Piraeus, and Las Palmas). For degree centrality (number of adjacently connected neighbors), Rotterdam followed by Antwerp rank at the top of the global hierarchy, with 472 and 398 links respectively. This statistical distribution is less hierarchical than that of layers as only 86 ports have one single neighbor. All in all, the understanding 
ports by their traffic diversity appears to be more fruitful than based on more classical measures like total throughput or connectivity.

\section{Conclusion}

This complex network approach to the multilayered structure of the global maritime network is fruitful in many ways. It confirms the overwhelming importance of the most diversified ports, which handle the bulk of global trade and by their high centrality act as pivots towards smaller ports. Port activity as a whole is thus highly influenced by the ability of maritime nodes to embed within multiple circulation layers. Such layers, despite their differences in terms of respective market coverage, operation, and technology, thus converge at a few large hubs and gateways, Rotterdam and Singapore being the cores of this multilayered hierarchy. In turn, the whole global network remains rather disorganized and sparsely connected when considering only specialized nodes, as the different parts of the world stand at distance from each other, linked by tiny links or being in isolation. The removal of the most diversified ports, by iteration, thus makes the global network highly vulnerable. This is in line with complex network research where multilayered networks are more vulnerable when layers couple with each other at high-degree nodes (Vespignani, 2010). This effect of diversity is particularly keen when assembling ports belonging to the same urban area, the port city rather than the port itself or the terminal being the unit of analysis. Node aggregation is thus a necessary complement to the study of network diversity and networks in general (Tsiotas and Polyzos, 2018).

The lessons learned for ports and shipping are twofold. First, economies of scale in many sectors such as bulks and containers reached such a level that only a few ports are capable to welcome giant ships and to centralize flows that are bound to be redistributed towards smaller ports or the hinterland. This hub function tends to act as a magnet towards other traffic types, thereby making port systems highly unequal in terms of traffic and connectivity distribution. Second, not all ports may be able to attract all sorts of traffic. This depends greatly on the nature of their initial specialization, as ports may have been able to diversify their activity over time. Another insight of this research is the fact that multilayered connectivity is geographically circumscribed except, perhaps, in the case of Singapore, which mainly acts as a transshipment hub. This confirms that the port hierarchy closely relates with the intermingling of the different scales of flows, from the local to the global, in a stylized system (de Langen et al., 2002) that complements the multilayered system made of different traffic types. Our research thus confirmed that specialization, size, connectivity, but also geographic scale, are closely related within a highly hierarchical network. Large, diversified, well-connected ports connect over farther distances than others. This means that maritime traffic is likely to be captured and retained by such large pivots at the expense of other ports, which shall remain specialized in a few traffic categories.

There are policy implications of such results. In Europe for instance, the over-concentration of maritime traffic at a few large gateways exceeds by far the EU territorial objectives of regional balance and the territorial harmonization of the trans-European transport network. Traffic polarized by Antwerp, Rotterdam, and Hamburg creates bottlenecks despite multimodal alternatives to trucking, Antwerp for instance being France's main port through road transport. Those large gateways keep investing in massive port infrastructures to cope with demand, reinforcing the diversion of their southern, northern, and eastern counterparts by major shipping companies. This traffic overconcentration is a well-known, reinforcing phenomenon, notably in the case of container flows (Notteboom, 2010), with important implications on the location of value-added activities such as EDCs (Ferrari et al., 2006). The European port policy has not been able yet to modify such a landscape, 
notably given the relative failure of the EU Marco Polo programmes destined to enhance coastal shipping and the role of secondary ports. As underlined by de Langen (1998) small and medium-sized ports serve local hinterlands while large ports and hubs create economies of scale and agglomeration effects. Yet, small and medium-sized ports have several advantages such as land availability and cheaper cost. But such ports shall not strive to become large hubs; instead, they should attract valueadded activities and traffic in the bulk and breakbulk sectors (de Langen, 1998). In the container business, diseconomies of scale in large hubs / load centers due to congestion may create opportunities for smaller ports to develop this market and attract direct calls from shipping lines (see an early discussion by Hayuth, 1981).

Further research shall focus on the temporal dimension of the relationship between specialization, size, and connectivity. This shall open new ways of understanding the emergence of multilayered hubs, by questioning the place-dependencies and path-dependencies at stake. Place-dependency refers to the ability of particular ports to diversify their traffic portfolio. Thus, the search for the determinants of such a process are worth of investigation. Path-dependency is the degree of affinity among the different layers, as ports specialized in a particular sector will be more likely to attract other sectors. This calls for further dialogues with evolutionary economic geography, where the socio-economic diversification of regions has been investigated using data on firms and employment (Neffke et al., 2011). Another avenue of research is to complement maritime network analysis by hinterland aspects, as port competition and hierarchy is not solely based on shipping patterns. This suggests that the maritime network should not studied in an abstract topological space, but as a system embedded within territorial structures, where nodes are characterized by additional attributes such as local socioeconomic features. Such an extension of the analysis may face difficulties however, due to the scarcity of information about the true origins and destinations of maritime flows.

\section{References}

Baird, Alfred. 2010. "Redefining Maritime Transport Infrastructure." Proceedings of the ICE - Civil Engineering 163 (5): 29-33. https://doi.org/10.1680/cien.2010.163.5.29

Barabasi, Albert-László, and Réka Albert. 1999. "Emergence of Scaling in Random Networks." Science 286 (5439): 509-512. doi:10.1126/science.286.5439.509

Barrat, A., M. Barthelemy, R. Pastor-Satorras R., and A. Vespignani. 2004. "The Architecture of Complex Weighted Networks." Proceedings of the National Academy of Sciences 101 (11): 3747-3752. https://doi.org/10.1073/pnas.0400087101

Bartholdi, J.J., P. Jarumaneeroj, and A. Ramudhin. 2016. "A New Connectivity Index for Container Ports." Maritime Economics and Logistics 18 (3): 231-249. https://doi.org/10.1057/mel.2016.5

Charlier, J. 1994. "Sur le Concept de Tonnages Pondérés en Economie Portuaire. L'Exemple du Northern Range. » Les Cahiers Scientifiques du Transport 29: 75-84.

de Langen, P.W. 1998. "The Future of Small and Medium Sized Ports. in Marine Engineering and Ports, Water Studies Series, edited by G. Sciutto G. and C.A. Brebia, pp. 263-279, Boston and Southampton: WIT Press, Computational Mechanical Publications, First International Conference. Doi: 10.2495/MAR980251

de Langen, P.W., M. Nijdam, and M.R. Van der Horst. 2007. "New Indicators to Measure Port Performance." Journal of Maritime Research 4 (1): 23-36. 
de Langen, P.W., L.M. Van der Lugt, and J.H.A. Eenhuizen. 2002. "A Stylized Container Port Hierarchy: A Theoretical and Empirical Exploration." Paper presented at the International Association of Maritime Economists (IAME) Conference, Panama, November 13-15.

Ducruet, C. 2013. "Network Diversity and Maritime Flows." Journal of Transport Geography 30: 77-88. https://doi.org/10.1016/i.jtrangeo.2013.03.004

Ducruet, C. 2017. Multilayer Dynamics of Complex Spatial Networks: The Case of Global Maritime Flows (1977-2008)." Journal of Transport Geography 60: 47-58. https://doi.org/10.1016/i.jtrangeo.2017.02.007

Ducruet, C. 2020. "Revisiting Urban Hierarchy and Specialization from a Maritime Perspective." Maritime Policy and Management 47 (3): 371-387. https://doi.org/10.1080/03088839.2019.1693065

Ducruet, C., and H. Itoh. 2016. Regions and Material Flows: Investigating the Regional Branching and Industry Relatedness of Port Traffic in a Global Perspective." Journal of Economic Geography 16 (4): 805-830. https://doi.org/10.1093/jeg/lbv010

Ducruet, C., H.R.A. Koster, and D.J. Van der Beek. 2010. "Commodity Variety and Seaport Performance." Regional Studies 44 (9): 1221-1240. https://doi.org/10.1080/00343400903167904

Ducruet, C., and T.E. Notteboom. 2012. "The Worldwide Maritime Network of Container Shipping: Spatial Structure and Regional Dynamics." Global Networks 12 (3): 395-423. https://doi.org/10.1111/j.1471-0374.2011.00355.x

Duranton, G., and Puga D. 2000. "Diversity and Specialisation in Cities: Why, Where and When Does it Matter?" Urban Studies 37: 533-555. https://doi.org/10.1080/0042098002104

Ferrari, C., F. Parola, and E. Morchio .2006. "Southern European Ports and the Spatial Distribution of EDCs." Maritime Economics and Logistics 8: 60-81. https://doi.org/10.1057/palgrave.mel.9100150

Fleming, D.K., and Hayuth Y. 1994. "Spatial Characteristics of Transportation Hubs: Centrality and Intermediacy." Journal of Transport Geography 2: 3-18. https://doi.org/10.1016/0966$\underline{6923(94) 90030-2}$

Frazila, R.B., and F. Zukhruf. 2015. "Measuring Connectivity for Domestic Maritime Transport Network." Journal of the Eastern Asia Society for Transportation Studies 11: 2363-2376. https://doi.org/10.11175/easts.11.2363

Frémont, A., and Ducruet C. 2005. "The Emergence of a Mega-Port: The Case of Busan, From the Local to the Global." Tijdschrift voor Economische En Sociale Geografie 96 (4): 421-432. https://doi.org/10.1111/j.1467-9663.2005.00473.x

Frémont, A., and M. Soppé. 2004. "Les Stratégies des Armateurs de Lignes Régulières en Matière de Dessertes Maritimes." Belgeo 4: 391-406. https://doi.org/10.4000/belgeo.13429

Fujita, M., and T. Mori. 1996. "The Role of Ports in the Making of Major Cities: Self-Agglomeration and Hub-Effect." Journal of Development Economics 49: 93-120. https://doi.org/10.1016/0304$\underline{3878(95) 00054-2}$

Haezendonck, E., C. Coek, and A. Verbeke. 1999. "Value Added Analysis (VAA) as a Tool for Strategic Port Planning." Bulletin of the Permanent International Association of Navigation Congresses 100: 28-68. 
Hayuth, Y. 1981. "Containerization and the Load Center Concept." Economic Geography 57 (2): 160-176. doi:10.2307/144140

Hu, Y., and D. Zhu. 2009. "Empirical Analysis of the Worldwide Maritime Transportation Network." Physica A 388 (10): 2061-2071. https://doi.org/10.1016/j.physa.2008.12.016

Huang, Y., T. Hossein Rashidi, and L. Gardner. 2016. "Modelling the Global Maritime Container Network." Maritime Economics and Logistics 20: 400-420. https://doi.org/10.1057/s41278-016-0047$\underline{3}$

Kaluza, P., A. Kölzsch, M.T. Gastner, and B. Blasius. 2010. "The Complex Network of Global Cargo Ship Movements." Journal of the Royal Society Interface 7 (48): 1093-1103. https://doi.org/10.1098/rsif.2009.0495

Makkonen, T., M. Salonen, and S. Kajander. 2013. "Island Accessibility Challenges: Rural Transport in the Finnish Archipelago." European Journal of Transport Infrastructure Research 13 (4): 274-290. https://doi.org/10.18757/ejtir.2013.13.4.3005

Marti, B.E. 1985. "Chilean Ports: Commodity Specialization and Potential for Containerization." The Professional Geographer 37: 320-328. https://doi.org/10.1111/j.0033-0124.1985.00320.x

McCalla, R.J., B. Slack, and C. Comtois. 2004. "The geographical hierarchy of container shipping networks in the Caribbean basin and Mediterranean Sea." Paper presented at the 10th World Conference on Transport Research (WCTR), Istanbul, July 4-8.

Neffke, F., M. Henning, and R. Boschma. 2011. "How do Regions Diversify Over Time? Industry Relatedness and the Development of New Growth Paths in Regions." Economic Geography 87 (3): 237-265. https://doi.org/10.1111/i.1944-8287.2011.01121.x

Newman, M. (2010) Networks. An Introduction. Oxford: Oxford University Press.

Ng, A.K.Y., and C. Ducruet. 2014. "The Changing Tides of Port Geography (1950-2012)." Progress in Human Geography 38 (6): 785-823. https://doi.org/10.1177/0309132513516178

Notteboom, T.E. 2006. "Traffic Inequality in Seaport Systems Revisited." Journal of Transport Geography 14 (2): 95-108. https://doi.org/10.1016/i.jtrangeo.2004.12.003

Notteboom, T.E. 2010. "Concentration and the Formation of Multi-Port Gateway Regions in the European Container Port System: An Update." Journal of Transport Geography 18 (4): 567-583. https://doi.org/10.1016/i.jtrangeo.2010.03.003

Notteboom, T.E., and J.P. Rodrigue. 2005. "Port Regionalization: Towards a New Phase in Port Development." Maritime Policy and Management 32 (3): 297-313. https://doi.org/10.1080/03088830500139885

Pais Montes, C., M.J. Freire Seoane, and F. Gonzalez-Laxe. 2012. "General Cargo and Containership Emergent Routes: A Complex Networks Description." Transport Policy 24: 126-140. https://doi.org/10.1016/j.tranpol.2012.06.022

Pan, J.J., M.G.H. Bell, K.F. Cheung, S. Perera, and H. Yu. 2019. "Connectivity Analysis of the Global Shipping Network by Eigenvalue Decomposition." Maritime Policy and Management 46 (8): 957-966. https://doi.org/10.1080/03088839.2019.1647587

Parshani, R., C. Rozenblat, D. letri, C. Ducruet, and S. Havlin. 2010. "Inter-Similarity Between Coupled Networks." Europhysics Letters 92: 68002. https://doi.org/10.1209/0295-5075/92/68002 
Peng, P., S. Cheng, and F. Lu. 2020. "Characterizing the Global Liquefied Petroleum Gas Trading Community Using Mass Vessel Trajectory Data." Journal of Cleaner Production 252: 119883. https://doi.org/10.1016/j.jclepro.2019.119883

Peng, P., J.P. Poon, Y. Yang, F. Lu, and S. Cheng. 2019. "Global Oil Traffic Network and Diffusion of Influence Among Ports Using Real Time Data." Energy 172: 333-342. https://doi.org/10.1016/j.energy.2019.01.118

Rimmer, P.J. 1966. "The Problem of Comparing and Classifying Seaports." The Professional Geographer 18 (2): 83-91. https://doi.org/10.1111/i.0033-0124.1966.00083.x

Rimmer, P.J. 2007. "Port Dynamics Since 1965: Past Patterns, Current Conditions and Future Directions." Journal of International Logistics and Trade 5 (1): 75-97.

Rimmer, P.J., and C. Comtois. 2005. "China's Extra- and Intra-Asian Liner Shipping Connections, 19902000." Journal of International Logistics and Trade 3: 75-97.

Rodrigue, J.P., and T.E. Notteboom. 2010. "Foreland-Based Regionalization: Integrating Intermediate Hubs with Port Hinterlands." Research in Transportation Economics 27 (1): 19-29. https://doi.org/10.1016/i.retrec.2009.12.004

Rodrigue, J.P., and T.E. Notteboom. 2013. "The Geography of Cruises: Itineraries, not Destinations." Applied Geography 38: 31-42. https://doi.org/10.1016/j.apgeog.2012.11.011

Rodrigue, J.P., and T.E. Notteboom. 2020. "Maritime Transportation." in: The Geography of Transport Systems, edited by J.P. Rodrigue J.P., https://transportgeography.org/?page id=1762 (Accessed July 2020).

Slack, B., and E. Gouvernal. 2015. "Container Transshipment and Logistics in the Context of Urban Economic Development." Growth and Change 47 (3): 406-415. https://doi.org/10.1111/grow.12132

Tongzon, J.L. 1995. "Determinants of Port Performance and Efficiency." Transportation Research Part A 29 (3): 245-252. https://doi.org/10.1016/0965-8564(94)00032-6

Torbianelli, V.A. 2000. "When the Road Controls the Sea: A Case Study of Ro-Ro Transport in the Mediterranean." Maritime Policy and Management 27 (4): 375-389. https://doi.org/10.1080/030888300416568

Tsiotas, D., and S. Polyzos. 2015. "Analyzing the Maritime Transportation System in Greece: A Complex Network Approach." Networks and Spatial Economics 15 (4): 981-1010. https://doi.org/10.1007/s11067-014-9278-y

Tsiotas, D., and S. Polyzos. 2018. "Effects in the Network Topology due to Node Aggregation: Empirical Evidence from the Domestic Maritime Transportation in Greece." Physica A 491: 71-88. https://doi.org/10.1016/j.physa.2017.08.130

Vespignani, A. 2010. "Complex Networks: The Fragility of Interdependency." Nature 464: 984-985. https://doi.org/10.1038/464984a

Wang, N., N. Wu, L.L. Dong, H.K. Yan, and D. Wu. 2016. "A Study of the Temporal Robustness of the Growing Global Container-Shipping Network." Nature Scientific Reports 6 (34217): doi: 10.1038/srep34217

Zaidi, F. 2011. Analysis, Structure and Organization of Complex Networks. Saarbrücken: LAP Lambert Academic Publishing. 


\begin{tabular}{|l|r|r|}
\hline \multicolumn{1}{|c|}{ Type } & \multicolumn{1}{c|}{ DWT } & No. Vessels \\
\hline Asphalt & 570858 & 87 \\
\hline Cement & 2103367 & 237 \\
\hline Chemical & 22267820 & 1704 \\
\hline Container & 88685571 & 2861 \\
\hline Crude oil & 156307458 & 899 \\
\hline Cruise & 1338189 & 279 \\
\hline Dry bulk & 239459187 & 4344 \\
\hline Fishing & 626096 & 468 \\
\hline Gas & 19653941 & 733 \\
\hline General cargo & 31505614 & 6945 \\
\hline Livestock & 601309 & 103 \\
\hline Oil tanker & 29573756 & 1183 \\
\hline Ores & 24055332 & 120 \\
\hline Other & 1700108 & 777 \\
\hline Other tanker & 11484089 & 250 \\
\hline Passenger & 741248 & 425 \\
\hline Reefer & 6021456 & 802 \\
\hline Service & 1219908 & 756 \\
\hline Vehicle & 13317907 & 1247 \\
\hline Wood & 4511878 & 101 \\
\hline Total & 655745094 & 24321 \\
\hline
\end{tabular}

Appendix 1: World fleet under study 


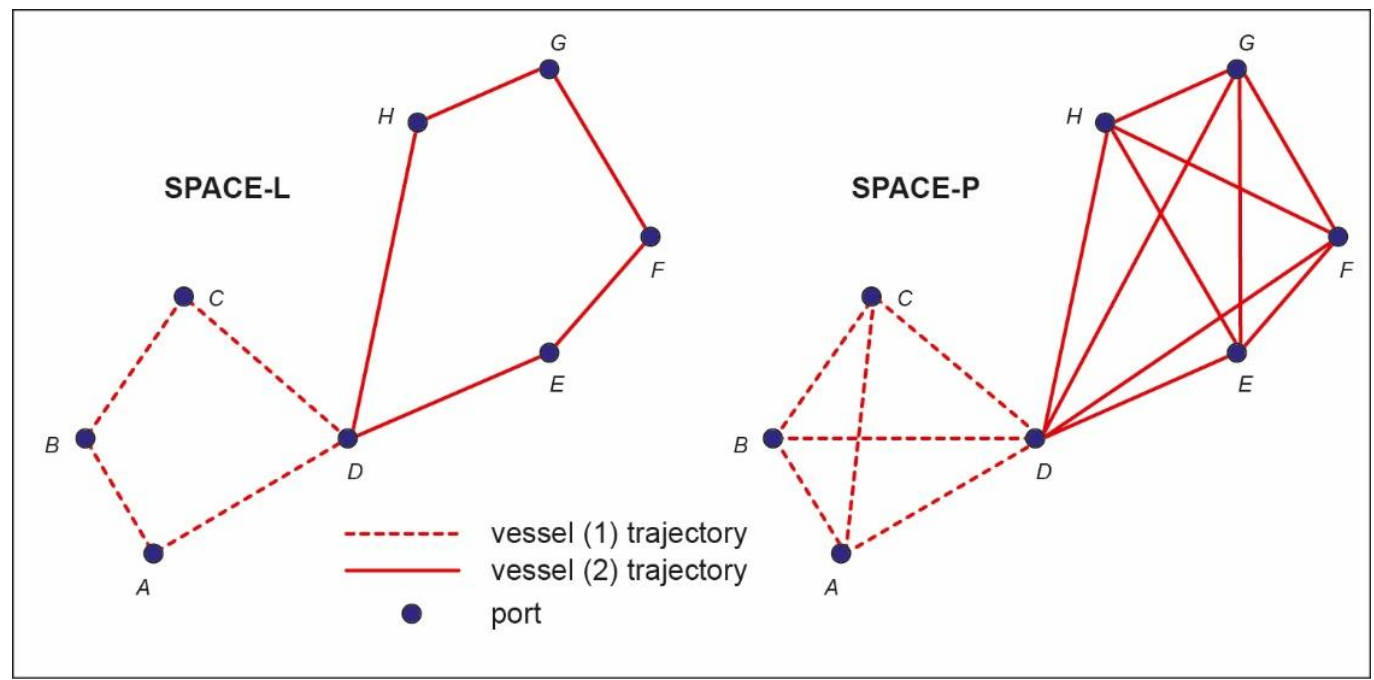

Figure 1: Analytical framework for network construction

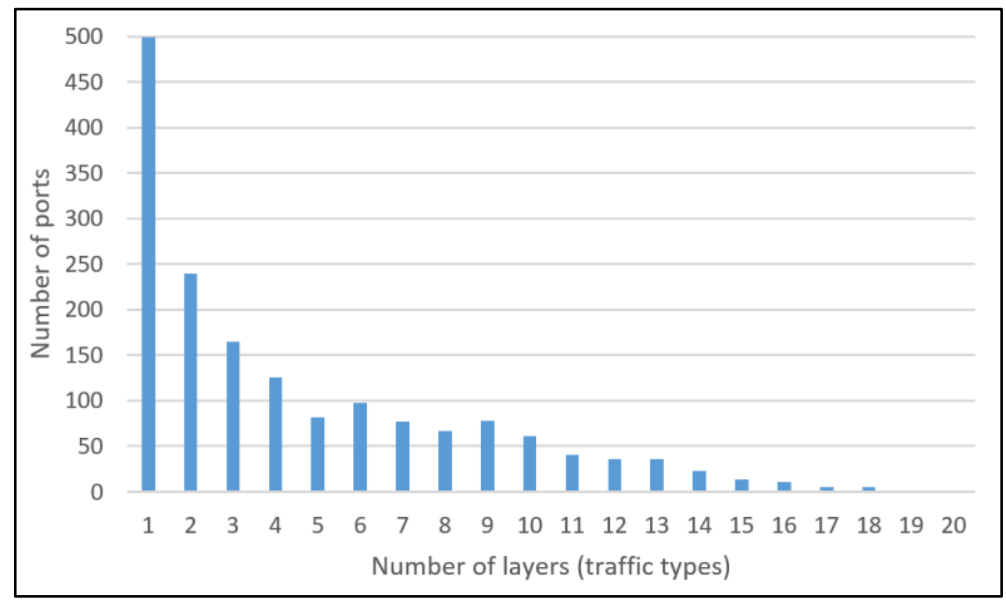

Figure 2: Distribution of ports and their number of traffic types

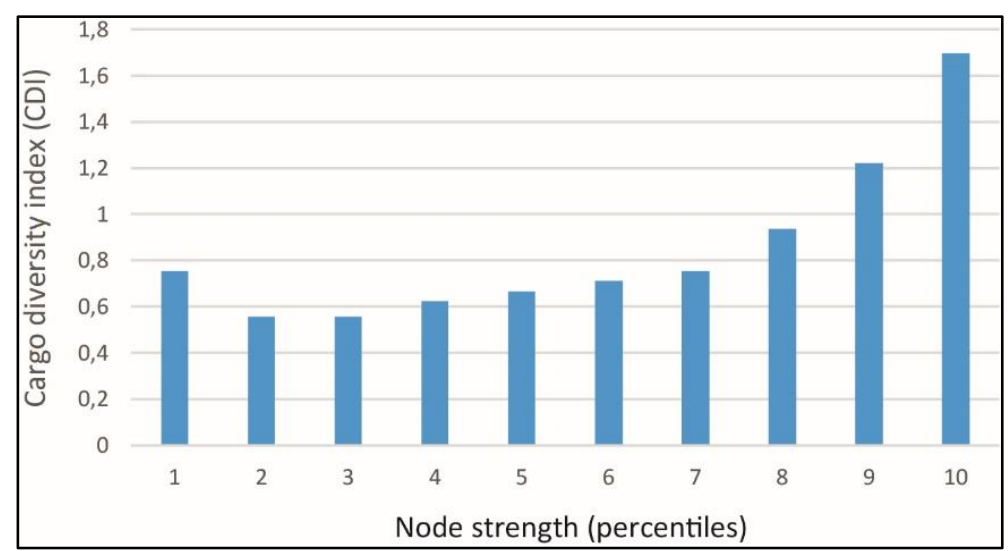

Figure 3: Traffic diversity and traffic volume 


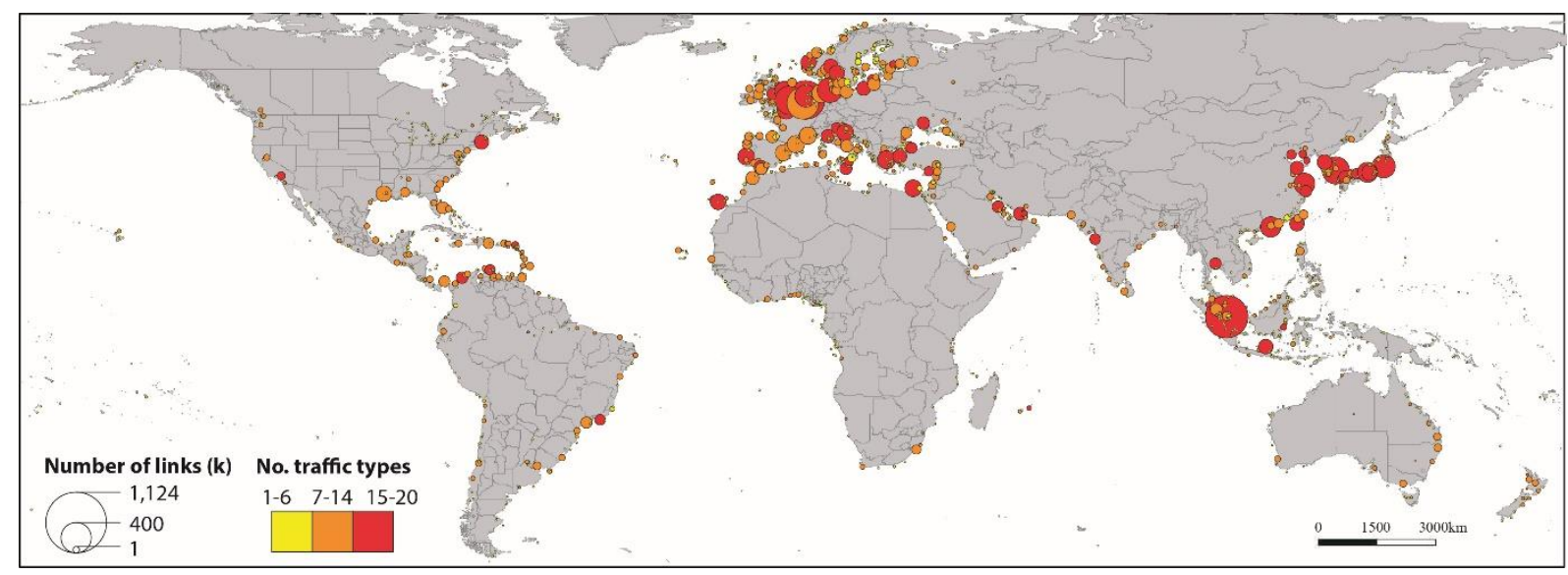

Figure 4: World distribution of traffic diversity and port connectivity
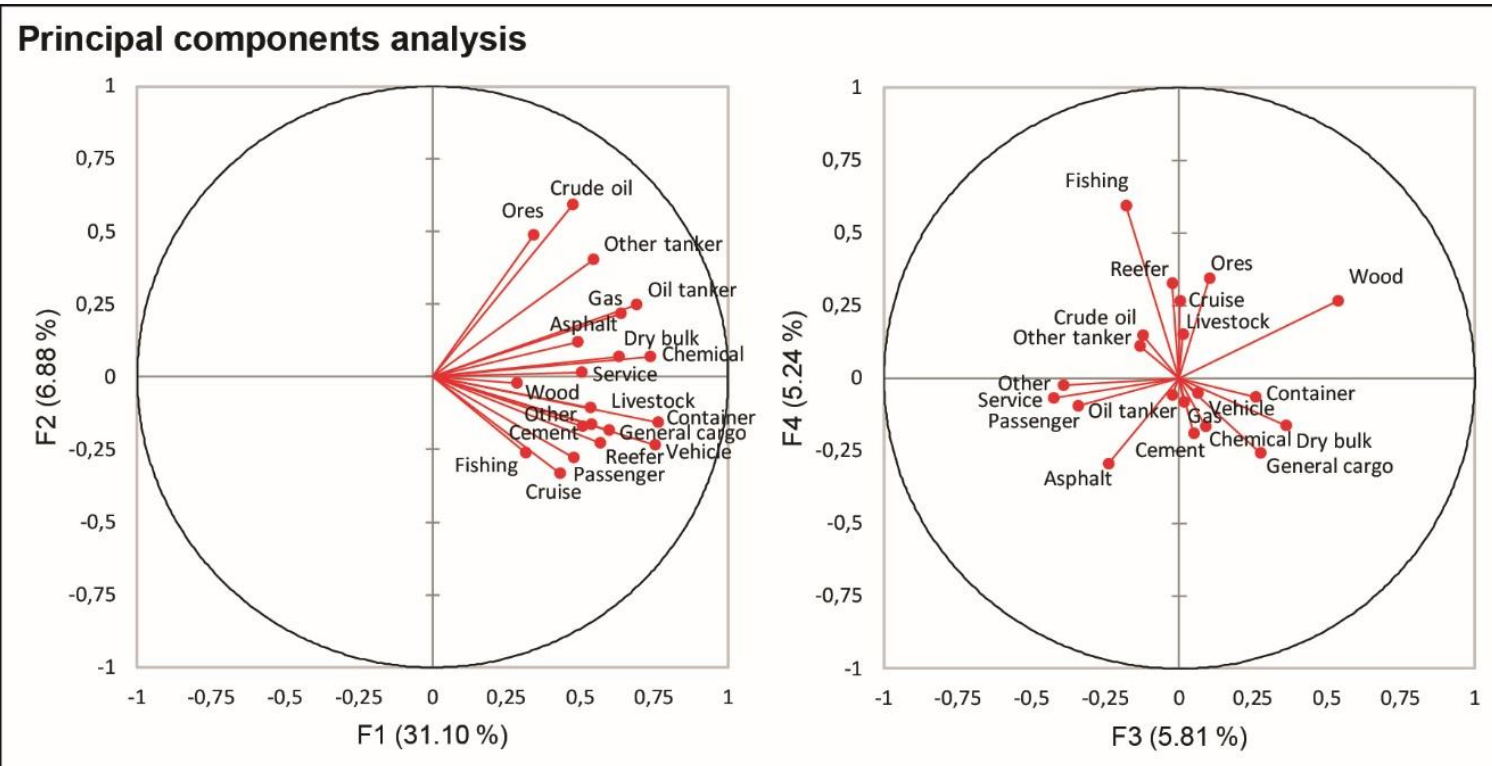

\section{Cluster analysis}

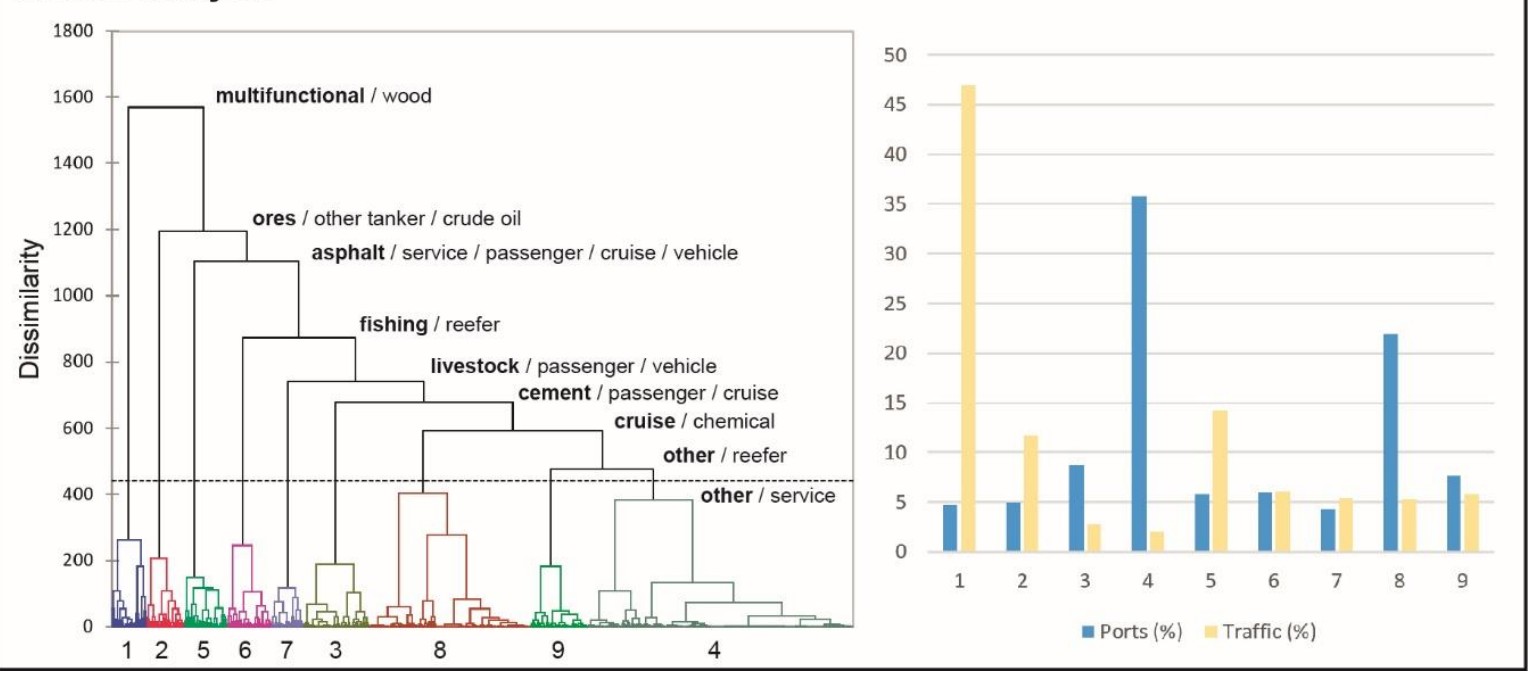

Figure 5: Principal components analysis of port specialization 

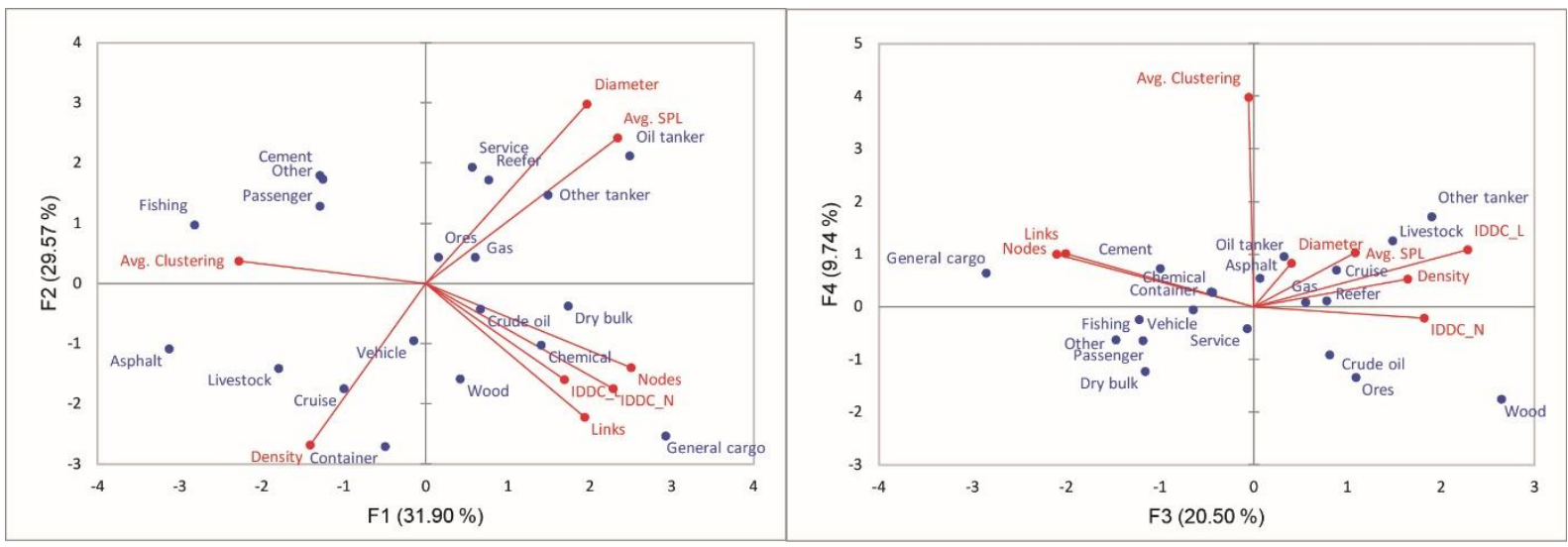

Figure 6: Principal component analysis of cargo traffic layers

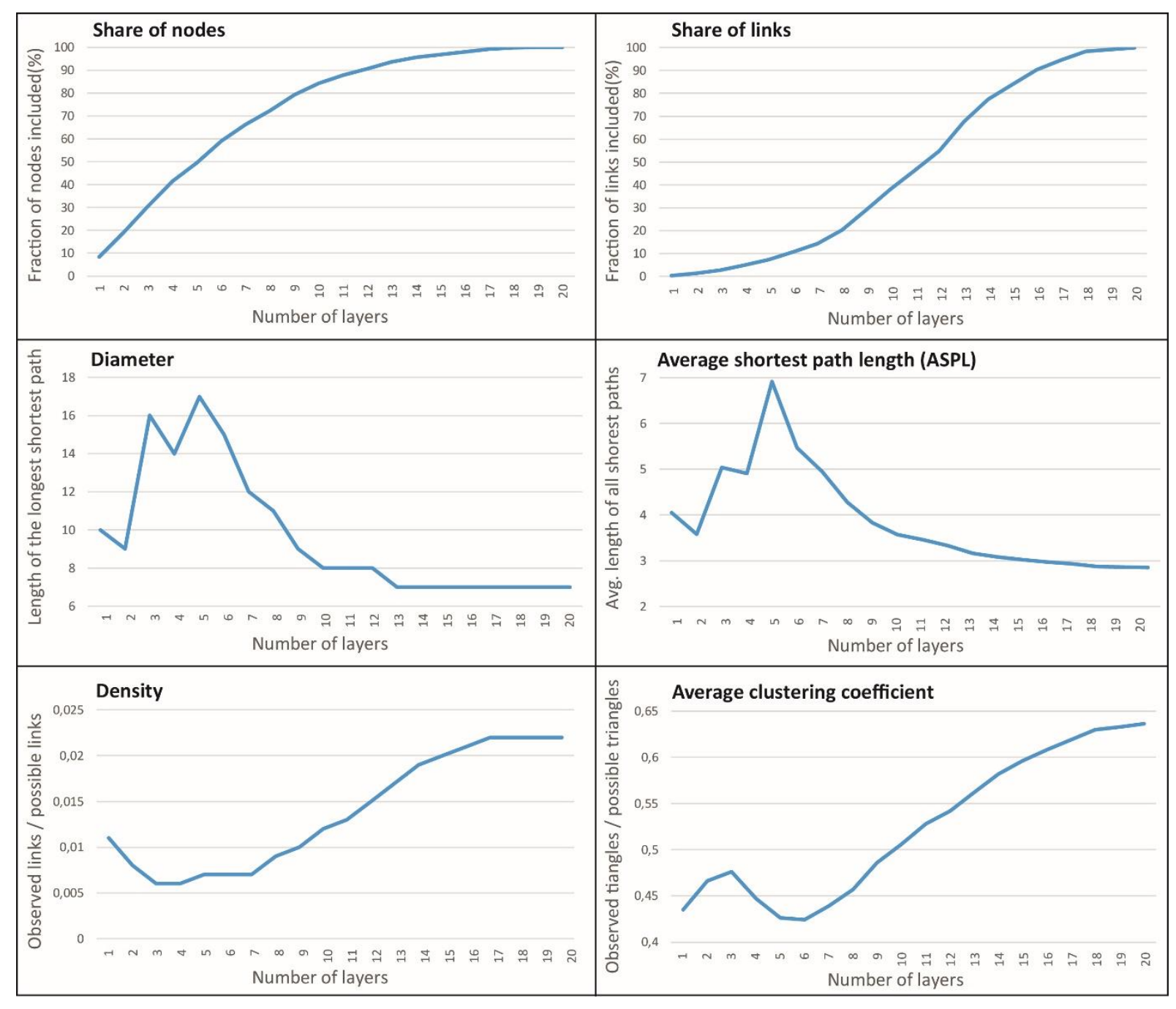

Figure 7: Structural properties of network layers 


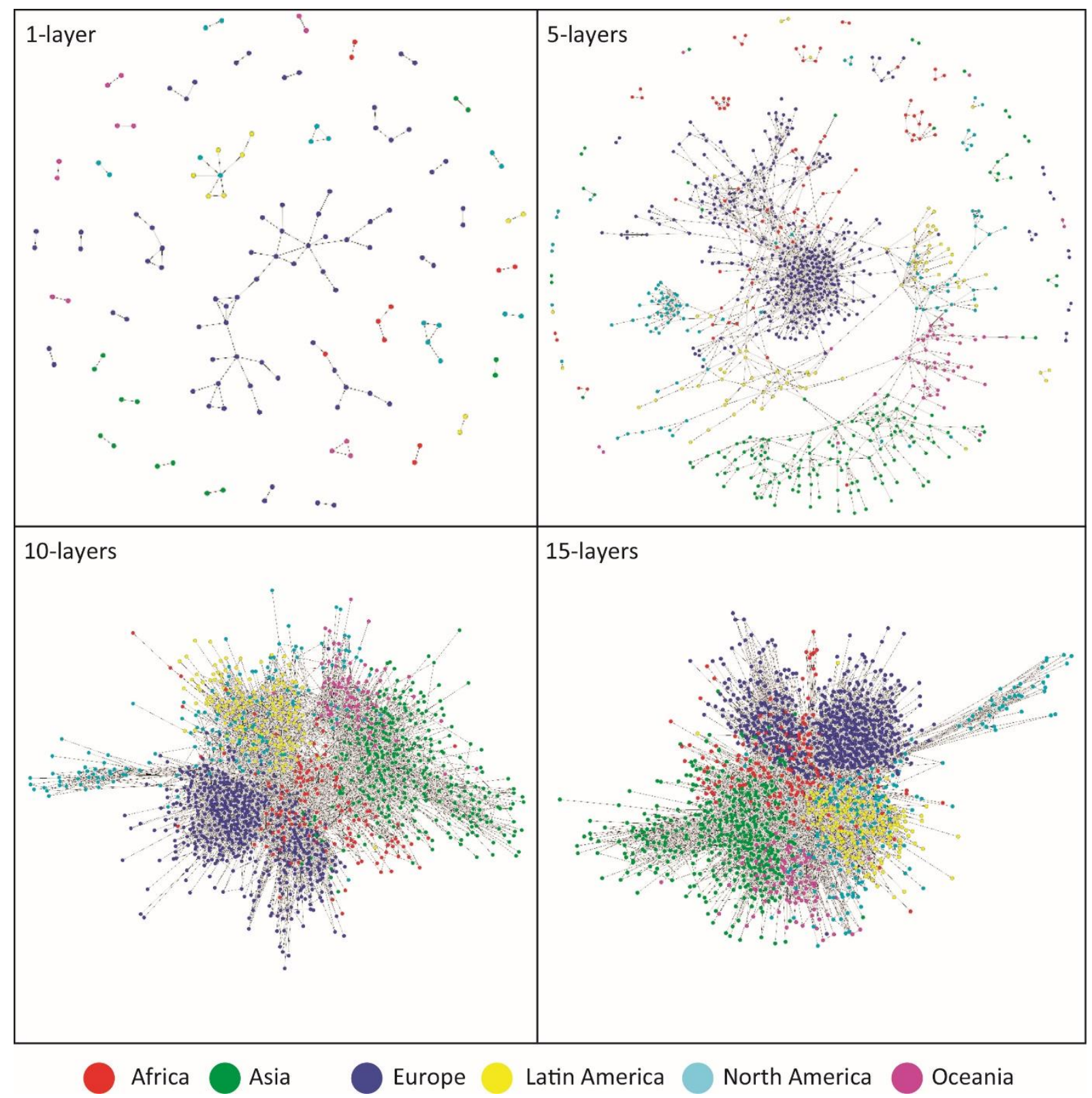

Figure 8: Graph visualization of selected network layers 

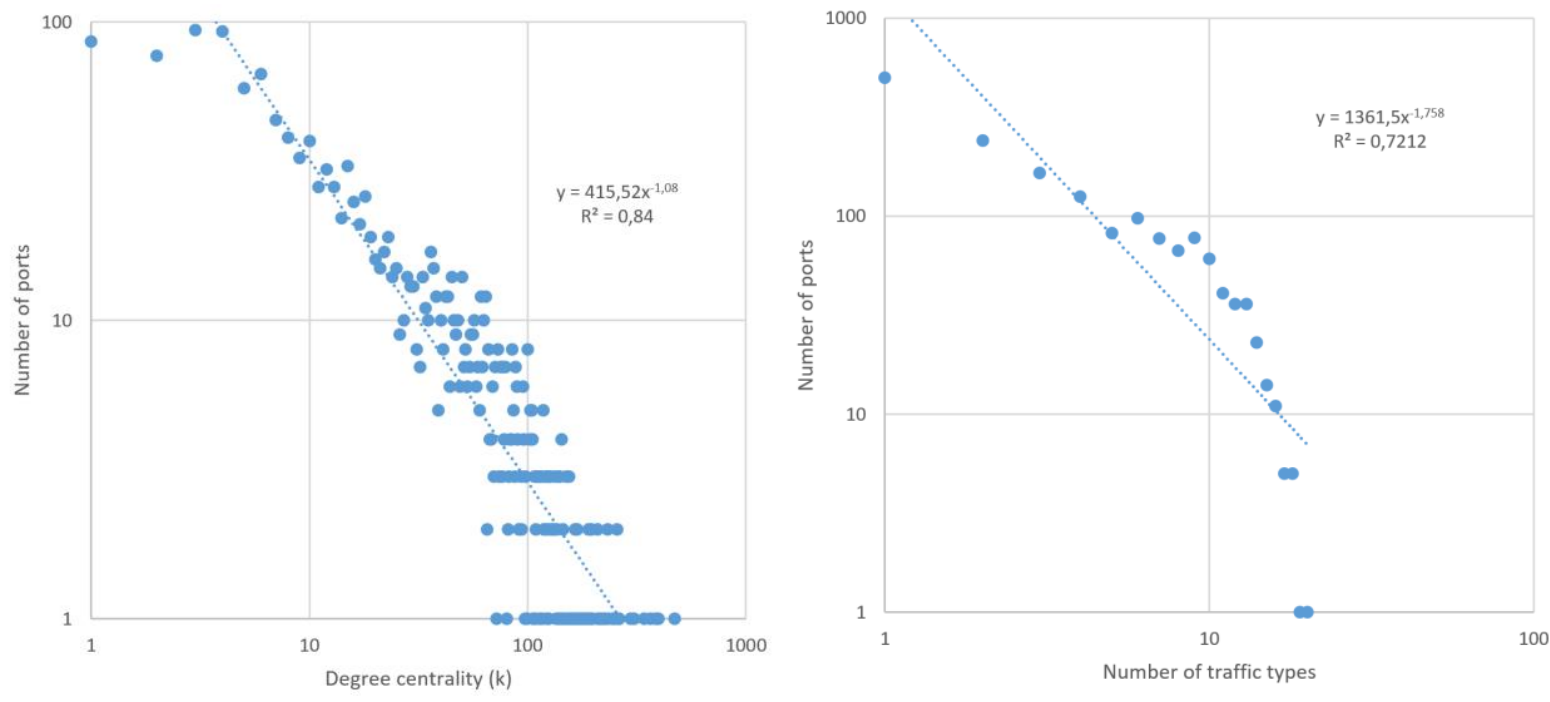

Figure 9: Hierarchical structure of the global maritime network

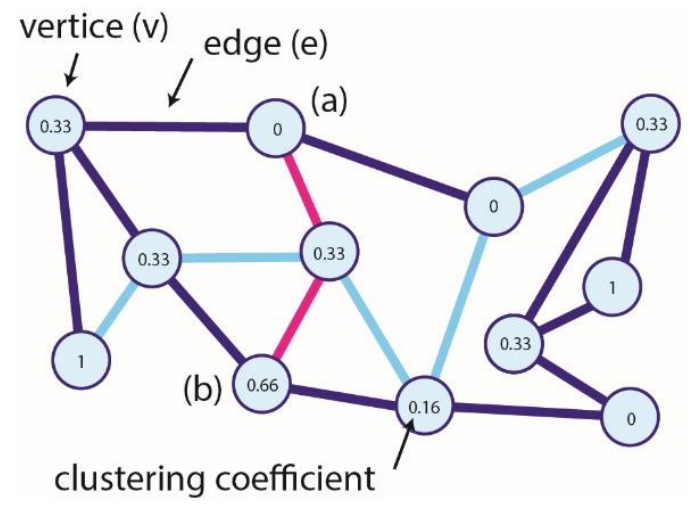

shortest path between ( $a$ ) and $(b)=2$ diameter $=\mathbf{5}$ average shortest path length $\mathbf{=} \mathbf{2 . 4 2 4}$ density $=\frac{e}{\frac{(v *(v-1)}{2}}=0.277$ average clustering coefficient $=\mathbf{0 . 3 7 4}$

Appendix 2: Methodology for the calculation of network indices 